\title{
PALEOVENTOS E PALEOCORRENTES SUBAQUOSAS DO SISTEMA DEPOSICIONAL PIRAMBÓIA NOS ESTADOS DE SÃO PAULO E PARANÁ, BACIA DO PARANÁ: ESTUDO BASEADO EM ANÁLISE ESTATÍSTICA DE DADOS AZIMUTAIS
}

\author{
PAULO CÉSAR FONSECA GIANNINI ${ }^{1}$, ANDRÉ OLIVEIRA SAWAKUCHI', \\ LUIZ ALBERTO FERNANDES ${ }^{2} \&$ LEANDRO MENEZES DONATTI ${ }^{3}$
}

\begin{abstract}
PALEOWINDS AND SUBAQUEOUS PALEOCURRENTS OF THE PICAMBÓIA DEPOSITIONAL SYSTEM IN THE STATES OF SÃO PAULO AND PARANÁ, PARANÁ BASIN: A STUDY BASED ON STATISTICAL ANALYSIS OF DIP DIRECTIONS Cross stratification dip directions data distributed along the outcrop area of the Pirambóia eolian depositional system (Permian and/ or Triassic of Paraná Basin), in the states of São Paulo and Paraná, South Brazil, were grouped according to stratigraphic interval, geographic position and depositional facies criteria. Paleowinds and subaquous paleocurrents directions were estimated from eolian and subaqueous (coastal and/or fluvial) facies data, through statistical analysis. The geographic distribution of these paleocurrents and paleowinds directions, during the development of the Pirambóia system, is discussed in terms of provenance and paleogeography, including aspects of atmospheric circulation and relief. The paleowind pattern shows a convergence zone, in the State of Paraná, characterized by eolian influx from NW and NE, in the northern area, and from SW, in the southern area. During the development of Pirambóia depositional system. this zone migrates from the central to the south-central portion of the Paraná State. About the subaqueous facies for the lower Pirambóia depositional system, the paleocurrents exhibit provenance from NE in the southwest of São Paulo State and north of Paraná State. Bidirectional paleocurrents (NNE-SSW) are observed in the central-eastern area of São Paulo State. For the upper Pirambóia depositional system, the paleocurrents found are from SE in the northern São Paulo State, and from NE and NNE in the central and southern areas of Paraná State. Paleocurrents with high dispersion, without a main dip direction, were observed in the central-eastern portion of São Paulo and northern Paraná. The observed paleowind pattern reflects air mass convergence, in global or regional scale of atmospheric circulation. In the regional scale, this convergence would be related to blockade exerted by a geographic barrier in Paraná, which acted as an obstacle to the southern winds, in its north flank, and to the northern winds, in its southern flanks. The coincidence between the zone with reversal of paleowinds and subaquous paleocurrents and the area with concentration of rudaceous facies and with thinning of the stratigraphic unit are suggestive of the existence of structural highs internally to the basin during the development of the Pirambóia depositional system.
\end{abstract}

Keywords: Pirambóia Formation, eolian depositional system, paleocurrents, paleowinds

Resumo Medidas de mergulho de estratificações cruzadas tomadas ao longo da faixa aflorante dos depósitos do sistema deposicional eólico Pirambóia (Permiano e/ou Triássico da Bacia do Paraná) nos estados de São Paulo e Paraná foram agrupadas segundo critérios escalonados de fatiamento estratigráfico, posição geográfica e fácies deposicionais. A partir das medidas agrupadas faciologicamente como eólicas e subaquosas (fluviais ou costeiras), inferiram-se respectivamente os rumos de paleoventos e paleocorrentes através da aplicação de testes de hipóteses estatísticas. A distribuição espacial dos paleoventos e paleocorrentes subaquosas assim inferidos, no decorrer da atividade do sistema, é objeto de análise e discussão, em termos de proveniência e paleogeografia, incluindo aspectos de circulação atmosférica e relevo. Os paleoventos configuram uma zona de convergência no Estado do Paraná, caracterizada por influxo eólico de NW e NE, a norte, e de SW, a sul. Ao longo do período de desenvolvimento do sistema Pirambóia, esta zona de convergência teria migrado da porção norte para a centro-norte do estado. No que se refere às fácies subaquosas, durante o intervalo de tempo correspondente à metade inferior do registro do sistema, as paleocorrentes viriam de NE. no sudoeste de São Paulo e norte do Paraná, e apresentariam padrão bipolar (NNE-SSW) no centro-leste paulista. Para o período de tempo correspondente à metade superior, foram determinadas paleocorrentes subaquosas de SE, no norte de São Paulo, e de NE a NNE. no centro e sul do Paraná. No centro-leste paulista e norte paranaense, observam-se paleocorrentes subaquosas com dispersão elevada, sem rumo preferencial. O padrão de paleoventos reflete convergência de massas de ar, em escala de circulação atmosférica global e/ou regional, neste último caso relacionada a bloqueio exercido por barreira geográfica no Paraná, que serviria de obstáculo aos ventos de sul, na porção norte, e aos ventos de norte, na porção sul. A coincidência geografica entre as áreas de inversão de paleoventos e paleocorrentes subaquosas, de concentração preferencial de fácies rudáceas e de adelgaçamento da unidade são indícios da existência de paleoaltos estruturais internos à bacia, durante o desenvolvimento do sistema.

Palavras-chave: Formação Pirambóia, sistema deposicional eólico, paleocorrentes, paleoventos

INTRODUÇÃO Medidas de rumo de mergulho de estratificações cruzadas constituem a ferramenta clássica de inferência de paleofluxo sedimentar. Como se trata de dados amostrais, o méto- do requer o emprego de recursos estatísticos, incluindo testes de hipóteses.

Em escala regional ou de bacia sedimentar, o potencial

1 - Departamento de Geologia Sedimentar e Ambiental, Universidade de São Paulo, Rua do Lago, 562, Cidade Universitária, CEP 05508-080, São Paulo -SP, Brasil; e-mails: pcgianni@usp.br; andreos@usp.br

2 - Departamento de Geologia, Universidade Federal do Paraná, Centro Politécnico, CEP 81531-990, Curitiba - PR, Brasil: e-mail: lufernandes@ufpr.br 3. Petrobras, Universidade Corporativa, Rua General Canabarro, 50), Maracanã, Rio de Janeiro - RJ, Brasil; email: Iedonatti@petrobras.com.br 
interpretativo dos resultados de paleofluxo eólico (paleoventos) e subaquoso (paleocorrentes) reside na reconstituição da paleogeografia, incluídos aí vários aspectos inter-relacionados, como as áreas fontes sedimentares, o paleorrelevo e o padrão de circulação atmosférica. No caso específico de depósitos continentais, paleocorrentes fluviais indicam a posição de paleoaltos e relacionam-se diretamente ao paleorrelevo, enquanto os paleoventos definem o padrão de circulação atmosférica na bacia, o qual pode também estar relacionado à conformação topográfica regional. Tanto paleocorrentes fluviais como paleoventos fornecem a posição das áreas fontes. Os dois tipos de dados complementam-se e inter-relacionam-se, o que facilita o exame de consistência interna das interpretações geológicas deles extraídas.

A proposta deste trabalho é inferir rumos de paleofluxo sedimentar do sistema deposicional Pirambóia (sensu Donatti et al. 2001) a partir da análise estatística sistemática dos rumos de mergulho de estratificações cruzadas, obtidas em intervalos estratigráficos pré-defïnidos, e em ampla área geográfica, correspondente à porção aflorante da unidade nos estados de São Paulo e Paraná.

\section{FORMAČ̃̃O PIRAMBÓIA E SISTEMA DEPOSICIONAL} PIRAMBÓIA Estratigrafia e sistemas deposicionais De início, os depósitos da Formação Pirambóia foram tratados indiferenciadamente dentro dos arenitos Botucatu, termo proposto por Gonzaga de Campos (1889 apud Bigarela \& Salamuni, 1961) para designar os depósitos com estratificações cruzadas de grande porte, sotopostos ou intercalados a derrames basálticos da serra de Botucatu, no Estado de São Paulo. Pacheco (1927 apud Paraguassu, 1968) introduziu o termo Camadas Pirambóia para referir-se a argilitos, siltitos e arenitos argilosos aflorantes nos arredores de Pirambóia (SP). Em função da mapeabilidade então mal definida desta nova unidade, alguns autores à época interpretaram os Arenitos Pirambóia como camadas intercaladas dentro da unidade Botucatu. Com o objetivo de separar as duas unidades, Washburne (1930) utilizou a designação Arenito Botucatu sensu strictu para referir-se à unidade superior de arenitos considerados eólicos, e o termo Arenito Pirambóia, para referirse à unidade inferior, tida como subaquosa. Mais tarde, com base no fato de que o termo Pirambóia sempre estivera associado à deposição subaquosa, Soares (1975) proporia formalmente o uso da designação Formação Pirambóia. O topo da unidade litoestratigráfica assim designada estaria imediatamente abaixo de uma fácies rudácea basal da Formação Botucatu. Caetano-Chang et al. (1991), estudando a Formação Pirambóia na serra de São Pedro (SP), reconheceram a presença e o predomínio de estruturas típicas de deposição eólica. As fácies subaquosas teriam registro subordinado e incluiriam fácies areno-rudácea no topo da unidade.

Donatti et al. (2001) e Donatti (2002) subdividiram a sucessão arenácea pré e sin-vulcânica da Bacia do Paraná (Pirambóia mais Botucatu) nos estados de São Paulo e Paraná, em cinco associações de fácies. Da base para o topo, estas associações correspondem a: 1) lençóis de areia em planície de maré; 2) campo de dunas costeiro com planícies interdunares freqüentemente inundadas; 3) campo de dunas costeiro com planícies interdunares raramente inundadas; 4) planície aluvial com rios entrelaçados e dunas eólicas; e 5) dunas gigantes com depressões interdunares. As associações 1 a 4 representariam o registro de um sistema eólico úmido (i.e, campos de dunas com lençol freático próximo à superfície deposicional), o sistema Pirambóia. A associação 5 registraria o sistema eólico seco Botucatu. A equivalência entre estes dois sistemas e as formações Pirambóia e Botucatu, respectivamente, conforme definidas formalmente por Soares (1973), não é perfeita, em especial no que se refere ao posicionamento estratigráfico de fácies rudáceas presentes na passagem entre as duas unidades.

A idade atribuída à Formação Pirambóia tem sido atrelada à interpretação de suas relações de contato com as unidades acima e abaixo e à correlação com unidades da Bacia do Paraná aflorantes no Rio Grande do Sul. Às unidades subjacentes à Formação Pirambóia (Grupo Passa Dois), atribui-se idade permiana a eotriássica (Rohn 1994). A unidade sobrejacente (Formação Botucatu) interdigita-se com derrames vulcânicos (Formação Serra Geral), datados como do início do Cretáceo (Turner et al. 1994).

Lavina \& Faccini (1993) correlacionam a Formação Pirambóia à Formação Sanga do Cabral (unidade da Bacia do Paraná aflorante no Rio Grande do Sul), cuja idade permiana é assegurada com base no conteúdo fossilífero.

Souza et al. (1971) descrevem a ocorrência de fragmentos vegetais fósseis de Lycopodiopsis derby na parte superior da Formação Pirambóia em Serrana (SP). Este fóssil é comumente encontrado nas camadas permianas do topo do Grupo Passa Dois em São Paulo (formações Teresina e Corumbataí). Assim, segundo Fúlfaro (1972), o achado fossilífero de Souza et al. (1971) permitiria propor a hipótese de inexistência de hiato deposicional entre o Grupo Passa Dois e a base da Formação Botucatu (sensu lato).

Admitindo uma passagem sem hiato deposicional com as unidades Teresina, Corumbataí e Serrinha (Fúlfaro \& Bósio 1968, Matos 1995, Donatti et al. 2001), o limite inferior da Formação Pirambóia estaria no Permiano ou Eotriássico. Em contraposição, para os autores que assumem uma discordância erosiva limitando a base da formação (Soares 1973, Rohn 1994, Caetano-Chang 1997), a sedimentação Pirambóia teria se iniciado apenas no Triássico ou Jurássico.

A ausência de consenso acerca do caráter do contato também está presente na passagem entre as formações Pirambóia e Botucatu. Não existem portanto idades precisas nem consensuais para o início e o fim da sedimentação Pirambóia. De aceitação geral, tem-se apenas que os depósitos desta unidade representam algum intervalo de tempo situado entre o Permiano e o Eocretáceo (Neocomiano).

Paleoventos e paleocorrentes Dentre os trabalhos clássicos sobre paleoventos nos depósitos eólicos pré-vulcânicos da Bacia do Paraná, destacam-se os de Bigarella \& Salamuni (1961) e Bigarella \& Van Eeden (1970/1971) em que se apresenta um grande número de medidas azimutais de estratificações cruzadas eólicas obtidas ao largo de quase toda a bacia. Os dados de Bigarella \& Salamuni (1961) referem-se ao Arenito Botucatu (sensu lato) nos estados de Minas Gerais, São Paulo, Paraná, Santa Catarina e Rio Grande do Sul e à unidade eólica crono-correlata no Uruguai (Arenito Tucuarembó). Os dados de Bigarella \& Van Eeden (1970/ 1971) abrangem os arenitos eólicos mesozóicos considerados crono-correlatos na Bacia do Parnaíba (Arenito Sambaíba, no Piauí) e na Bacia do Paraná (Arenito Botucatu, nos estados de Goiás, Mato Grosso, Minas Gerais, São Paulo, Paraná, Santa Catarina e Rio Grande do Sul, Arenito Missiones, no Paraguai e Arenito Tucuarembó, no Uruguai). Em ambos os conjuntos de dados, detecta-se predomínio de paleoventos de SW e de NE na Bacia do Paraná, com convergência destes dois rumos no centro-sul do 
Estado do Paraná, próximo à fronteira com o Estado de Santa Catarina.

Para o flanco nordeste da Bacia do Paraná, Soares (1973), baseado na interpretação da Formação Pirambóia como sistema fluvial meandrante, mediu paleocorrentes com rumo We SW.

Assine (1993) encontrou paleoventos de NW e NE e paleofluxo das fácies fluviais WNW, nos arredores de São Pedro (SP). Caetano-Chang (1997) indicou paleoventos de NW na porção inferior da unidade, rumo que persistiria, na porção mediana, com contribuição maior de NE. No topo, haveria domínio de paleoventos de NE e persistência do rumo de mergulho WNW nas fácies arenorudáceas correspondentes ao Arenito Itirapina.

Giannini et al. (1999) encontraram na Formação Pirambóia, em São Paulo e Paraná, padrão de convergência de paleoventos na região do arco de Ponta Grossa similar ao detectado por Bigarella \& Salamuni (1961) na Formação Botucatu sensu lato.

Métodos Bigarella (1970/1971) demonstrou que os azimutes médios de mergulho de estratificações cruzadas de dunas transversais, barcanóides ou parabólicas ativas na costa brasileira equivalem ao rumo dos ventos responsáveis pela geração destas dunas. Os rumos inferidos a partir das estratificações cruzadas refletiriam o padrão de circulação dos ventos de superfície atuantes na região costeira. Com base nisso, uma premissa metodológica básica deste artigo é a possibilidade de inferir rumos de paleoventos, e mesmo alguns elementos dos padrões de circulação atmosférica, a partir de medidas de rumo de mergulho de estratificações cruzadas eólicas.

As medidas obtidas foram agrupadas segundo critérios que permitissem a análise de paleocorrentes no espaço e no tempo. Para isso, utilizaram-se hierarquicamente três critérios de agrupamento: posição estratigráfica, região geográfica e fácies sedimentares (Fig. 1).

Agrupamento das medidas POSIÇÃOESTRATIGRÁFICA Os depósitos do sistema deposicional Pirambóia foram subdivididos em duas "fatias" estratigráficas de mesma espessura, metade inferior e metade superior. Um problema da subdivisão baseada na espessura reside na possibilidade de não haver significado cronoestratigráfico rigoroso. Entretanto, a dificuldade de correlacionar regionalmente superfícies de descontinuidade física dentro da unidade que pudessem ser tomadas como datum levou à subdivisão por espessura como alternativa de trabalho mais funcional para a análise da variação dos rumos de paleocorrentes ao longo do tempo.

REGIÃO GEOGRÁFICA Os dados da pesquisa foram obtidos em áreas previamente selecionadas (com boas exposições) na faixa aflorante do sistema Pirambóia nos estados de São Paulo e Paraná. Dentro de cada área, foram tomadas medidas em vários afloramentos distribuídos ao acaso. Com isso, os afloramentos estudados resultaram distribuídos em cinco ou seis aglomerados de pontos, separados entre si por dezenas de quilômetros. Cada aglomerado de pontos (destacado por círculo na Fig. 1) foi considerado um grupo de dados.

FÁCIES SEDIMENTARES As fácies onde foram obtidas medidas azimutais estão resumidas na Tabela I e ilustradas nas figuras 2 a 6.

As associações de fácies e de estruturas sedimentares desempenham papel importante nas interpretações de processos e sistemas deposicionais aqui sugeridas:

- A sucessão de séries da fácies AFMc (Fig. 2) indica o estabelecimento de campo de dunas ou draa. Sua associação com fácies de estratificação plano-paralela fluidificada e/ou rica em silte e argila, indicativa de interdunas com água, permite inferir deposição em sistema eólico úmido.

- A fácies Aci (Fig. 4), perante os modelos até hoje propostos para a Formação Pirambóia, pode ser diretamente interpretada como depósitos de canal fluvial retrabalhando lama da planície de inundação. No entanto, a associação com fácies sedimentar indicativa de processos subaquosos oscilatórios (arenito fino com marcas onduladas simétricas) torna possível interpretar sua deposição em corpo aquoso com extensão suficiente para o desenvolvimento de ondas, como por exemplo um grande lago, ou laguna ou baía submetida a regime de marés.
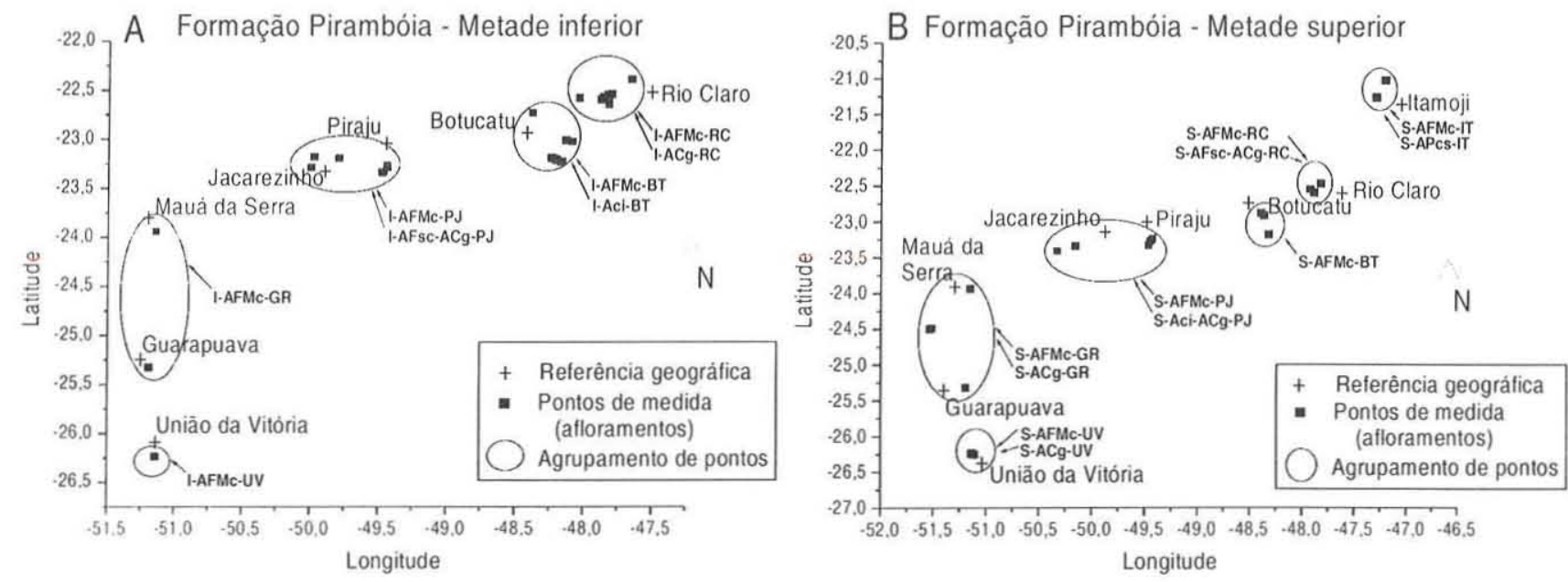

Figura I - Subdivisão das medidas de atitude de estratificação cruzada por "fatia" estratigráfica (diagrama inferior versus superior), posição geográfica (círculos) e fácies sedimentares (setas). Nas siglas utilizadas para designar as amostras (grupos de medidas), a primeira letra indica o intervalo estratigráfico (I para inferior e S para superior), o conjunto de letras em seguida indica as fácies, e as duas letras finais indicam a região. 
Tabela 1 - Sumário das fácies sedimentares onde foram tomadas medidas de rumo de mergulho de estratificações cruzadas.

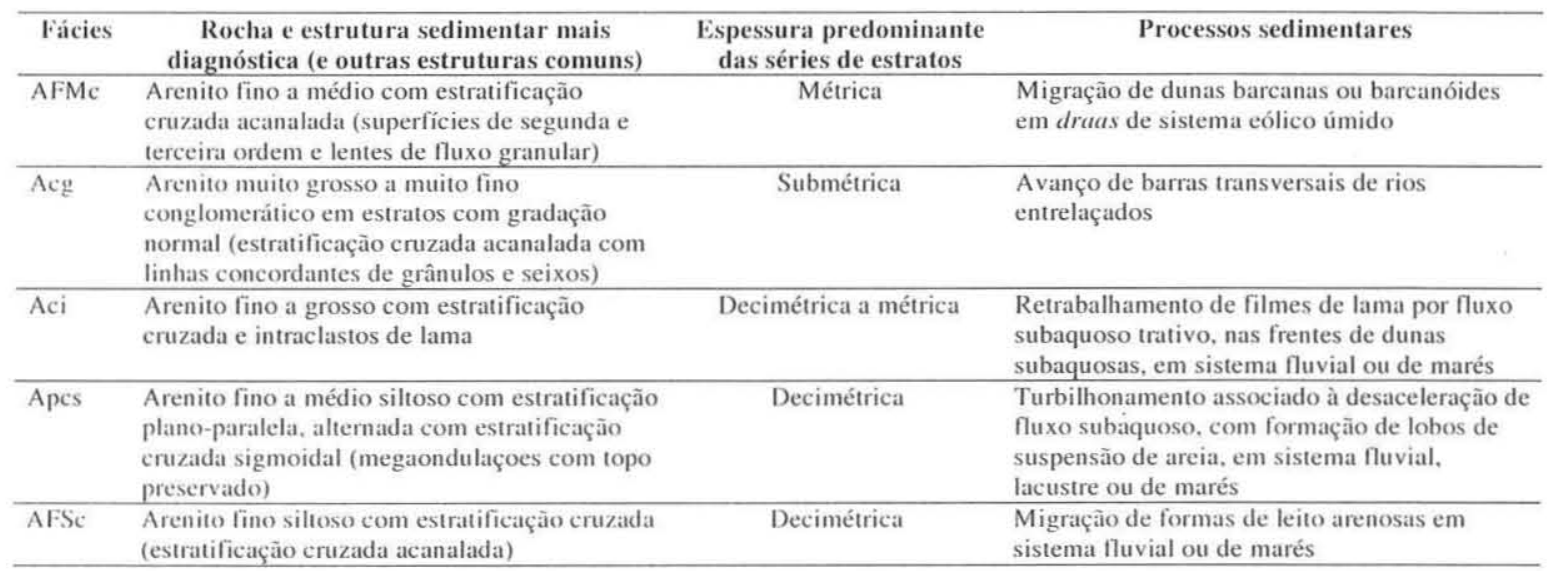

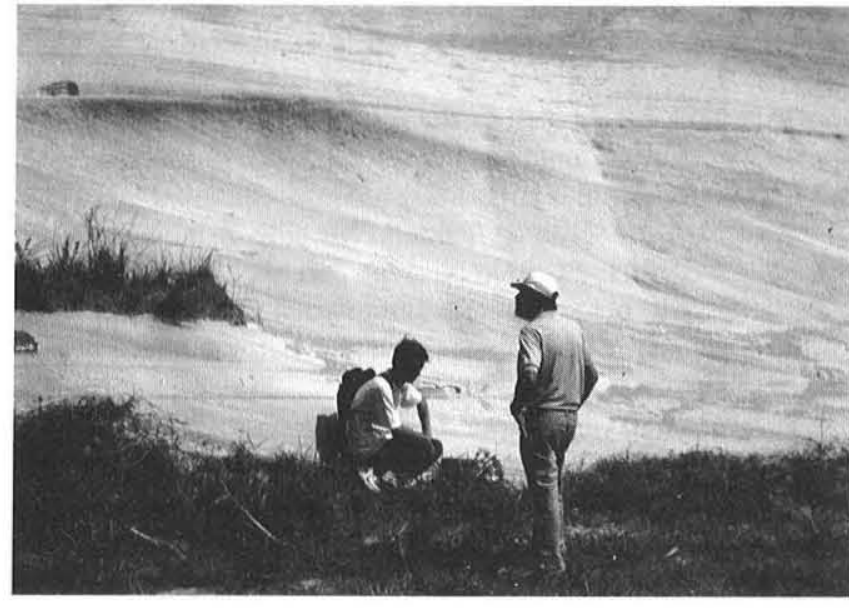

Figura 2 - Fácies AFMc (arenito fino a médio com estratificação cruzada acanalada em séries de espessura decimétrica a métrica), em corte da rodovia São Pedro - Charqueada, SP (UTM 1/94524/5530588).

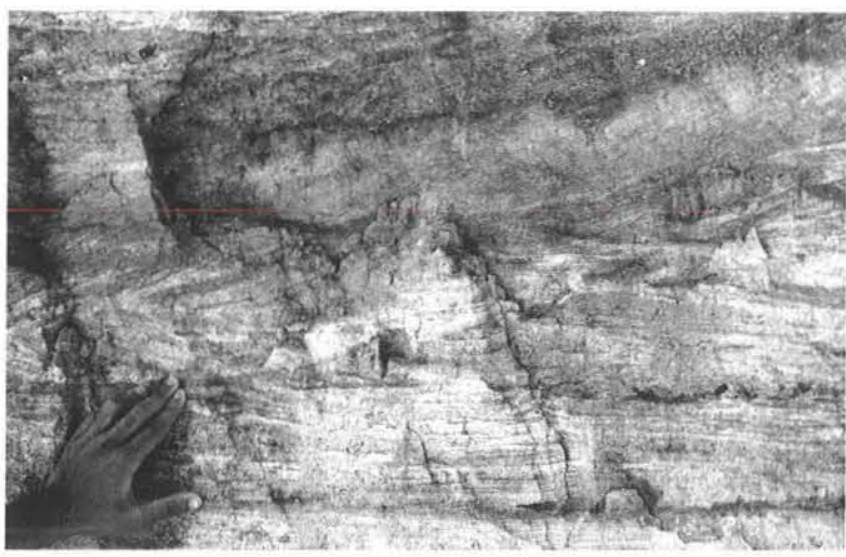

Figura 3 - Fácies Acg (arenitos conglomeráticos com estratos gradados), nos arredores da cidade de São Pedro, SP (UTM 199008/7503298).

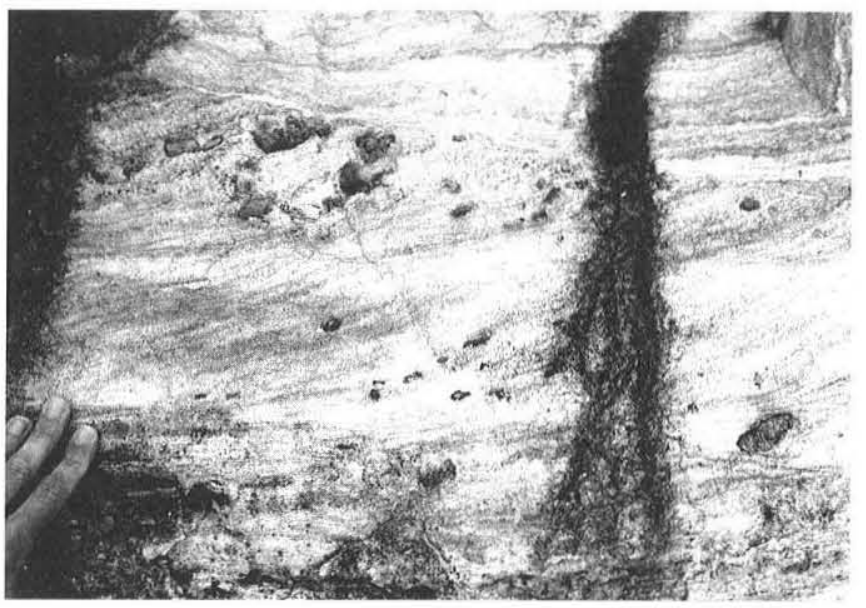

Figura 4 - Fácies Aci (arenito com estratificação cruzada acanalada e intraclastos de lama), nos arredores da cidade de São Pedro, SP (UTM 199008/7503298).

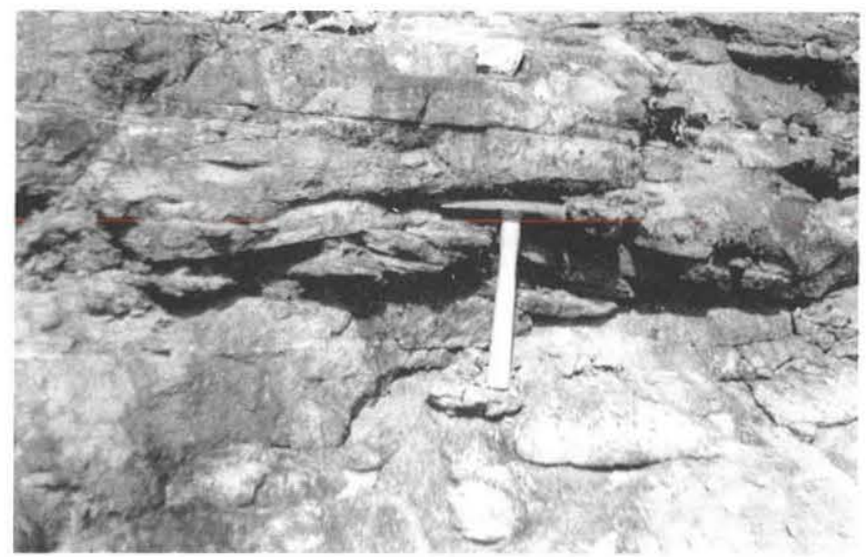

Figura 5 - Fácies Apcs (arenito com intercalaçãō de estratificação plano-paralela e estratificação cruzada sigmoidal), em corte da rodovia SP-351, próximo a Santo Antônio da Alegria, SP (UTM 270526/7673196). 


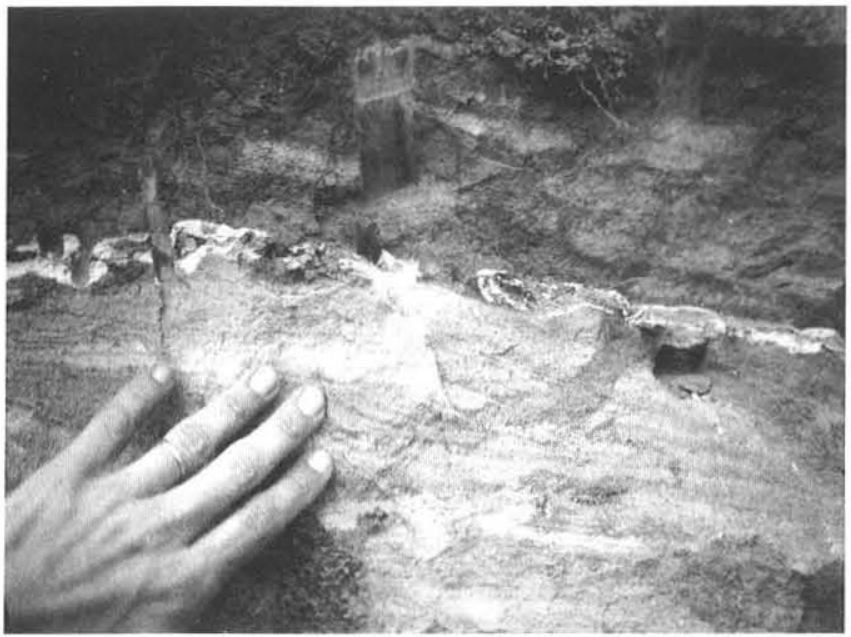

Fïgura 6 - Fácies AFSc (arenito fino, siltoso, com estratificação cruzada em séries submétricas), nos arredores de Sarutaiá, SP (UTM 655588/7418240).

- A fácies Apcs (Fig. 5) pode ser atribuída à migração de formas de leito subaquosas (estratificação cruzada sigmoidal), formadas pela chegada e desaceleração de fluxo trativo, com alta taxa de suspensão, em corpos de água rasos (estratificação planoparalela). Este contex to deposicional pode ocorrer em sistema fluvial, lacustre ou costeiro dominado por marés.

- Na fácies AFSc (Fig. 6), a concentração elevada de silte (maior que $20 \%$ ) e o pequeno porte das séries de estratificações são mais compatíveis com processos subaquosos que eólicos. A partir disso, a sua associação preferencial com outras fácies tipicamente subaquosas permite atribuí-la à migração de formas de leito arenosas em zonas de remanso de sistema fluvial entrelaçado ou de marés.

De acordo com estas interpretações, sintetizadas na Tabela 1, as fácies estudadas podem ser subdivididas em dois grupos quanto ao meio deposicional: subaéreo (eólico) e subaquoso. O grupo de meio eólico corresponde à fácies $\mathrm{AFMc}$, enquanto o de subaquoso inclui as fácies ACg, Aci, Apcs e AFSc.

Estimativa do rumo das paleocorrentes Para inferir o rumo do paleofluxo sedimentar a partir de estratificações cruzadas, deve-se supor que as estratificações foram geradas por formas de leito, cujo rumo de migração coincide com o rumo do paleofluxo. Assim, admite-se que a distribuição de frequiência dos rumos de merguIho de estratificações cruzadas possui valor preferencial, representado pelo azimute médio, que corresponderia ao rumo de migração das respectivas formas de leito.

ESTATÍSTICA DE DADOS DIRECIONAIS Para resumir os dados obtidos, foram calculadas as estatísticas $x_{o}$ (azimute médio, Equação 1) e $R_{0}$ (magnitude do vetor azimute médio, Equação 2) das amostras. Sendo $\theta$ uma variável azimutal, tem-se:

$$
\begin{aligned}
& x_{0}=\operatorname{arctg}\left(\frac{C_{n}}{S_{n}}\right) \\
& R_{0}=\sqrt{C_{n}^{2}+S_{n}^{2}} \\
& \text { Onde, } C_{n}=\frac{1}{n} \sum_{i=1}^{n} \cos \theta_{i} \text { e } S_{n}=\frac{1}{n} \sum_{i=1}^{n} \operatorname{sen} \theta_{i}
\end{aligned}
$$

A magnitude do vetor azimute médio $\left(R_{0}\right)$ é uma medida de dispersão análoga à variância, só que inversamente proporcional. Assim, quanto maior o valor de $R_{v}$, menor é a dispersão, e viceversa.

TESTE DE UNIFORMIDADE A inferência de paleoventos e paleocorrentes subaquosas depende da validade da hipótese de que os rumos de mergulho de estratificações cruzadas apresentam distribuição de freqüência tal que o azimute preferencial equivalha ao azimute médio. Testar esta hipótese corresponde a verificar se cada amostra (agrupamento de medidas) pertence a populações que seguem um modelo de distribuição de probabilidades do tipo Von Mises ou a uma população com distribuição uniforme. A distribuição de Von Mises é uma distribuição de probabilidades análoga à distribuição normal, só que para dados azimutais expressos por valores angulares (Mardia, 1972). Assim como a distribuição normal, a distribuição de Von Mises é uma distribuição unimodal e simétrica em torno da média. É caracterizada por dois parâmetros: azimute médio $\left(m_{0}\right)$ e concentração dos dados em torno do azimute médio $(\mathrm{k})$. Utiliza-se $\mathrm{M}\left(\mathrm{m}_{\mathrm{o}}, \mathrm{k}\right)$ como notação para denotar esta distribuição. $O$ parâmetro $k$ é proporcional à concentração dos dados em torno da média e pode ser estimado a partir da magnitude do vetor azimute médio $\left(R_{0}\right)$.

Seja $\theta_{l}, \ldots, \theta_{n}$ uma amostra aleatória proveniente de população cuja função densidade de probabilidades é $f(\theta)$, será testada a hipótese nula $\left(H_{0}\right)$ dada por:

$$
H_{0}: f(\theta)=\frac{1}{2 \pi} \text {, sendo } 0 \leq \theta \leq 2 \pi
$$

contra a hipótese alternativa $\left(H_{1}\right)$ dada por:

$$
H_{1}: f(\theta)=g(\theta)
$$

Assume-se que $g(\theta)$ corresponde a $M\left(\mathrm{~m}_{\sigma}, k\right)$. É admitido como pressuposto que $\mathrm{m}_{0}$ é desconhecido e que sob $H_{v}$, tanto $\mathrm{m}_{0}$ quanto $k$ são desconhecidos. A estatística utilizada no teste é $R_{v}$. Os valores críticos que limitam a aceitação da hipótese nula são tabelados em função do número de unidades na amostra $(n)$ e do nível de significância do teste (probabilidade de rejeitar a hipótese correta). Os detalhes deste teste e os valores críticos de $R_{o}$ podem ser encontrados em Mardia (1972).

O nível de significância (a) adotado foi de $1 \%$. Caso $R_{\text {Ocmanatral }}$ seja maior que $R_{\text {ocriticy, }}$, aceita-se a hipótese de que a amostra pertence a uma população com distribuição de Von Mises $\left(H_{1}\right)$. Portanto, a amostra terá um valor preferencial (azimute médio) que será utilizado como estimativa do rumo da paleocorrente. Caso contrário, a amostra pertencerá a população com distribuição uniforme $\left(H_{\theta}\right)$, ou seja, sem rumo preferencial.

TESTE DE EQUIVALENCIA ENTRE DUAS AMOSTRAS PERTENCENTES A POPULAÇÕES COM DISTRIBUIÇÃO DE VONMISES Foi utilizado um teste de hipóteses para decidir se os azimutes médios de duas amostras pertencentes a populações com distribuição de Von Mises e derivadas da mesma fácies (eólica ou subaquosa), porém de posição geográfica ou fatia estratigráfica diferentes, eram significativamente distintas. O objetivo desta comparação foi verificar se houve mudança no azimute dos paleoventos e paleocorrentes em função da posição geográfica e ao longo do tempo.

Supondo que $\theta_{i l}, \ldots, \theta_{i n}, i=1,2$ sejam amostras aleatórias independentes de tamanhos $n_{1}, n_{2}, \operatorname{com} M\left(\mathrm{~m}_{0, i}, k_{i}\right), i=1,2$, e que $x_{0 l}, x_{02}$ são os azimutes médios das amostras e $R_{0 l}, R_{02}$ as magnitudes dos vetores que representam estes azimutes, $\mathrm{O}$ azimute 
médio das duas amostras combinadas e a magnitude do vetor que representa este azimute são, respectivamente, $x_{t(t, 2)}$ e $R_{o x t .2)^{\circ}}$

Para testar a equivalência entre os azimutes médios, assumese que $k_{1}$ e $k_{2}$ são iguais a $k$. Foi testada a hipótese nula:

$$
H_{0}: \mu_{0.1}=\mu_{0.2}=\mu_{0} \text {, }
$$

contra a hipótese alternativa

$$
H_{1}: \mu_{0.1} \neq \mu_{0.2},
$$

onde $\mu_{0}$ e $k$ são desconhecidos.

O procedimento utilizado neste teste depende dos valores de $n_{1}, n_{2}$ e $R_{m t_{2}, 2}$, podendo classificar-se em quatro casos diferentes (I I IV̈).

Caso I: $0<R_{0(1.2)}<0,4 \wedge r<1 / 3$.

Caso II: $0<R_{0(1.2)}<0,4 \wedge 1 / 3<r<1 / 2$.

Caso III: $0,4<R_{0(1.2)}<0,7$ e valores moderados de $r$.

Caso IV: $R_{0(1.2)}>0,7$ e qualquer valor de $r$.

Para o caso I, deve-se construir um intervalo de confiança $(v)$ para a diferença

$$
d=\left|x_{0.1}-x_{0.2}\right| \text {. Para que } x_{0.1}=x_{0.2} \text {, o valor } d=0
$$
deve estar contido no intervalo de confiança $d \pm v$.

Nos casos II e III, utiliza-se a estatística $R_{D_{(L, 2)}}$ (Equação 4) O valor crítico de $R_{\theta_{1} i_{2},}$ foi estimado a partir da magnitude do vetor azimute médio das duas amostras agrupadas $\left(R_{(x), 2)}\right)$.

$$
R_{0(1.2)}^{\prime}=\frac{R_{1}+R_{2}}{n}
$$

onde, $R_{1}=R_{01} \times n_{1}, R_{2}=R_{02} \times n_{2}$ e $n=n_{1}+n_{2}$

O procedimento mais adequado para o Caso IV é a utilização da estatística $F$ dada por:

$$
F_{1, n-2}=(1+3 / 8 k)\left\{\frac{(n-2)\left(R_{1}+R_{2}-R_{0(1.2)}\right)}{n-R_{1}-R_{2}}\right\}
$$

onde $k$ é estimado a partir de $R_{(x, 1,2}$.

Os valores críticos de $R_{t o l, 2,}$ e $F$, assim como descrições mais pormenorizadas destes procedimentos, podem ser encontrados em Mardia (1972).

RESULTADOS Inferência estatística O teste de uniformidade indica que apenas três amostras (I-Aci-BT, na metade inferior, e SAFSc-ACg-RCe S-Aci-ACg-PJ, na metade superior) apresentam distribuição uniforme (Tabelas 2 e 3). Para as demais, é possível a atribuição de rumo preferencial de paleofluxo sedimentar. Os diagramas de distribuição geográfica dos paleofluxos assim obtidos para as metades inferior e superior do sistema deposicional Pirambóia encontram-se nas figuras 7 e 8, respectivamente.

A comparação entre rumos de paleofluxo de regiões adjacentes permite observar que, na metade inferior do sistema deposicional estudado, apenas os rumos inferidos para as regiões de Rio Claro (SP) e Botucatu (SP) não são significativamente diferentes entre si (Tabela 4). Já na metade superior, todos as regiões comparadas diferem estatisticamente entre si quanto ao rumo de paleofluxo (Tabelas 5 e 6).

A aplicação do mesmo teste de comparação para confrontar os rumos de paleofluxo sedimentar eólico da metade inferior e da metade superior do sistema Pirambóia também indica diferenças estatisticamente significativas. A maioria das amostras incide nos casos estatísticos II e III (Tabela 7).

Padrão de paleoventos Na metade inferior do sistema Pirambóia

\begin{tabular}{|c|c|c|c|c|c|c|}
\hline Amostra & $n$ & $x_{0}$ & $R_{\theta}$ & $\begin{array}{c}R_{\text {Prritico }} \\
\alpha=0.01\end{array}$ & $k$ (estimado) & $\begin{array}{c}\text { Distribuição } \\
\text { aceita no teste }\end{array}$ \\
\hline I-AFMc-RC & 166 & 184.77 & 0,31 & 0.21 & 0,65242 & Von Mises \\
\hline I-AFMc-BT & 185 & 173,35 & 0,52 & 0.21 & 1,22350 & Von Mises \\
\hline I-Aci-BT & 27 & 208,55 & 0,13 & 0,41 & 0,26223 & Uniforme \\
\hline 1-AFMc-PJ & 80 & 245,70 & 0,43 & 0,25 & 0,95440 & on Mises \\
\hline I-AFsc-ACg-PJ & 66 & 230,08 & 0,41 & 0.27 & 0,90043 & Von Mises \\
\hline 1-AFMc-GR & 39 & 28,915 & 0,49 & 0,34 & 1,09788 & Von Mises \\
\hline
\end{tabular}

Tabela 2 - Estatística descritiva e inferência de rumos de mergulho de estratificações cruzadas medidos na metade inferior do sistema Pirambóia. A última coluna à direita indica a distribuição aceita no teste de uniformidade.

Tabela 3 - Estatística descritiva e inferência de rumos de mergulho de estratificações cruzadas medidos na metade superior do sistema Pirambóia. A última coluna à direita indica a distribuição aceita no teste de uniformidade.

\begin{tabular}{lcccccc}
\hline \multicolumn{1}{c}{ Amostra } & $n$ & $x_{0}$ & $R_{0}$ & $\alpha=0.01$ & $k$ (estimado) & $\begin{array}{c}\text { Distribuiç̧ão } \\
\text { aceita no teste }\end{array}$ \\
\hline S-AFMc-IT & 114 & 3,96 & 0,37 & 0,21 & 0,79730 & Von Mises \\
S-Apcs-IT & 24 & 308,05 & 0,65 & 0,43 & 1,73945 & Von Mises \\
S-AFMc-RC & 36 & 125,43 & 0,54 & 0,35 & 1,29077 & Von Mises \\
S-AFsc-ACg-RC & 19 & 321,53 & 0,29 & 0,48 & 0,60625 & Uniforme \\
S-AFMc-BT & 20 & 222,27 & 0,71 & 0,47 & 2,07685 & Von Mises \\
S-AFMc-PJ & 40 & 178,27 & 0,67 & 0,34 & 1,84177 & Von Mises \\
S-Aci-ACg-PJ & 33 & 248,39 & 0,20 & 0,37 & 0,40828 & Uniforme \\
S-AFMc-GR & 32 & 242,62 & 0,82 & 0,37 & 3,14262 & Von Mises \\
S-ACg-GR & 32 & 240,13 & 0,69 & 0,37 & 1,95357 & Von Mises \\
S-AFMc-UV & 47 & 15,44 & 0,47 & 0,31 & 1,06810 & Von Mises \\
S-ACg-UV & 38 & 204,68 & 0,85 & 0,34 & 3,68041 & Von Mises \\
\hline
\end{tabular}

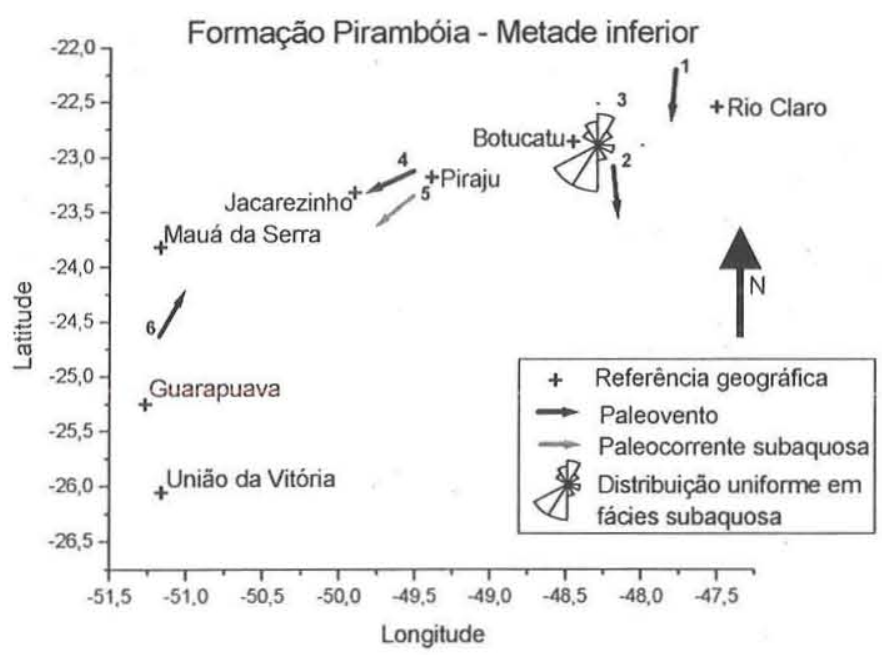

Figura 7 - Paleocorrentes inferidas a partir de medidas obtidas na metade inferior do sistema Pirambóia. As setas representam rumos preferenciais. A única amostra que apresentou distribuição uniforme encontra-se representada pela distribuição de frequiência dos dados. 1:I-AFMc-RC, 2:AFMc-BT, 3:I-Aci-BT, 4:I-AFMC-PJ, 5:I-AFSC-ACg-P.J, 6:I-AFMC-GR. 


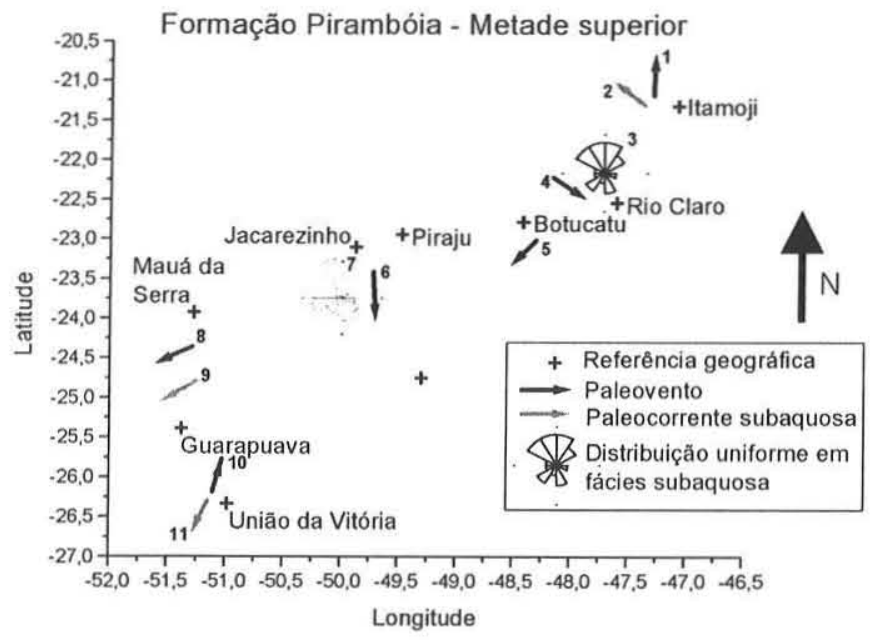

Figura 8 - Paleocorrentes inferidas a partir de medidas obtidas na metade superior do sistema Pirambóia. As setas representam rumos preferenciais. Amostras que apresentaram distribuição uniforme estão representadas pela distribuição de freqüência dos dados. 1:S-AFMc-IT, 2:S-Apcs-IT, 3:S-AFSc-ACg-RC, 4:S$A F M c-R C, 5: S-A F M c-B T, 6: S-A F M c-P J, 7: S-A c i-A C g-P J, 8: S-$ AFMC-GR, 9:S-Acg-GR, 10:S-AFMc-UV, 11:S-ACg-UV.

(Fig. 7), encontram-se paleoventos de $\mathrm{N}$ a NE desde o centro-leste de São Paulo (proximidades de Botucatu e Rio Claro) até o norte do Paraná (entre Jacarezinho, PR e Piraju, SP). Paleoventos de SW são observados a sul de Jacarezinho (PR), entre Mauá da Serra $(\mathrm{PR})$ e Guarapuava (PR). Este padrão evidencia uma zona de convergência de paleoventos no norte do Paraná, entre Jacarezinho e Mauá da Serra.

$\mathrm{Na}$ metade superior (Fig. 8), foram inferidos paleoventos de NW a NE na região delimitada por Rio Claro (SP), Mauá da Serra (PR) e Guarapuava (PR). No sul do Paraná (município de União da
Vitória), ocorrem paleoventos de S. Em comparação com a metade inferior, o rumo dos paleoventos medidos entre Mauá da Serra e Guarapuava (PR) inverte-se. Com isso, a zona de convergência, que na metade inferior encontrava-se próximo a Mauá da Serra, migra para sul. Nessa mesma fatia estratigráfica, paleoventos de $\mathrm{N}$ encontram-se também no norte de São Paulo (município de Itamoji).

Padrão de paleocorrentes As medidas de fácies subaquosas que admitiram rumo preferencial indicam paleocorrentes que variam aproximadamente de NW a SW (Tabelas 2 e 3; Figs. 7 e 8). Na metade inferior do sistema Pirambóia, predominam paleocorrentes para SW, com presença de distribuição aparentemente bipolar (sensu Tucker 2001) SSW-NNE (amostra 3, Fig. 7). Na metade superior, os rumos de paleocorrentes dividem-se entre NW, no norte e centroleste de São Paulo, e SW, no centro e sul do Paraná.

Discussão O padrão de convergência de paleoventos no centrosul paranaense aqui observado no sistema Pirambóia equivale ao já detectado por Giannini et al. (1999, 2000) na Formação Pirambóia, em mesma região, porém com menor quantidade de dados, e por Bigarella \& Salamuni (1961)e Bigarella \& Van Eeden (1970/1971), ao largo de quase toda a área de afloramento do Arenito Botucatu (sensu lato).

$\mathrm{O}$ registro de paleoventos com rumos opostos representa a atuação de duas massas de ar convergentes. Ambas atuariam sob condições propícias ao desenvolvimento de campos de dunas, isto é, suprimento de sedimento incoeso na granulação areia muito fina a média, disponível a ventos com velocidade e espaço de atuação suficientes para seu transporte (influxo) e com desaceleração adequada para sua deposição dentro do sistema (efluxo menor que influxo).

A perda de efluxo necessária para a formação de campos de dunas pode dar-se basicamente sob dois tipos de condições, isoladas ou combinadas: encontro de ventos convergentes e desaceleração por obstáculos topográficos (McKee 1982). Assim, em escala regional, qualquer padrão de paleoventos pode estar associado à paleodinâmica atmosférica global e/ou ao

Tabela 4 - Estatísticas utilizadas nos testes de comparação entre médias de duas amostras (casos II e III) pertencentes a regiões adjacentes (metade inferior do sistema Pirambóia).

\begin{tabular}{|c|c|c|c|c|c|c|c|c|c|c|c|c|c|}
\hline Amostras & $n_{1}$ & $n_{2}$ & $n_{1,2}$ & $r$ & $x_{\theta I}$ & $x_{02}$ & $x_{0(1,2)}$ & $R_{01}$ & $R_{02}$ & $R_{0\{1,2\}}$ & $R_{(x 1,2 y a b s}^{\prime}$ & $R_{(0(1,3) \text { critico }}^{\prime}$ & Resultado \\
\hline I-AFMc-RC(1) e I-AFMc-BT(2) & 166 & 185 & 351 & 0,47 & 184,77 & 173,35 & 177,34 & 0,31 & 0,52 & 0,42 & 0,42 & 0,42 & $x_{0 I}=x_{02}$ \\
\hline I-AFMc-BT(1) e I-AFMc-PJ(2) & 185 & 80 & 265 & 0,30 & 173,35 & 245,70 & 190.52 & 0,52 & 0,43 & 0,42 & 0.49 & 0,42 & $x_{01} \neq x_{02}$ \\
\hline I-AFMc-PJ(i) e i-AFMc-GR(2) & 80 & 39 & 119 & 0,33 & 245,69 & 28,915 & 275,94 & 0,43 & 0,49 & 0,19 & 0,45 & 0,23 & $x_{\theta 1} \neq x_{12}$ \\
\hline
\end{tabular}

Tabela 5 - Estatísticas utilizadas nos testes de comparação entre médias de duas amostras (casos II e III) pertencentes a regiões adjacentes (metade superior do sistema Pirambóia).

\begin{tabular}{|c|c|c|c|c|c|c|c|c|c|c|c|c|c|}
\hline Amostras & $n_{I}$ & $n_{2}$ & $n_{t, 2}$ & $r$ & $x_{i t}$ & $x_{m 2}$ & & $R_{\theta t}$ & $R_{02}$ & $R_{|x| .}$ & $R_{\text {tyl.2kats }}^{\prime}$ & $R_{\text {tQI.2/kritice }}^{\prime}$ & $\operatorname{Re}$ \\
\hline (1) $\mathrm{C} A \mathrm{~F}$ & 114 & 36 & 150 & 0,24 & 3,96 & 125,43 & 31,42 & 0,37 & 0,54 & 0,24 & 0,41 & 0,26 & \\
\hline$x$ & 36 & 20 & 56 & 0,36 & & & & 0,54 & 0,71 & & & & \\
\hline$r$ & 20 & 40 & 60 & 0,33 & & & & 0,71 & 0.67 & 0.64 & & & \\
\hline AFMc- & 40 & 32 & 72 & & & & & & & & & & \\
\hline & 32 & 47 & 79 & & & & & 0,82 & 0,47 & & & 0 & \\
\hline$A C g$ & 32 & 38 & 70 & 0,46 & 240,13 & 204,68 & 218,95 & 0,69 & 0,85 & 0,74 & $0, / 8$ & 0,75 & \\
\hline -Apcs-IT(1) e S-ACg-GR(2) & 24 & 32 & 56 & 0,43 & 308,05 & 240,13 & 267,59 & 0,65 & 0,69 & 0,56 & 0,67 & 0,59 & $x_{01} \neq x_{02}$ \\
\hline
\end{tabular}


Tabela 6 - Estatísticas utilizadas nos testes de comparação entre médias de duas amostras (Caso IV) pertencentes a regiöes adjacentes (metade superior do sistema Pirambóia).

\begin{tabular}{|c|c|c|c|c|c|}
\hline Amostra & $k$ & 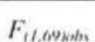 & $F_{\text {crition }}(\alpha=0,01)$ & $F_{\text {citition }}(\alpha=0,05)$ & Resultado \\
\hline S-ACg-GR(1) e S-ACg-UV(2) & 2,28930 & 20,68 & 7,080 & 4,000 & $x_{\theta 1} \neq x_{\theta 2}$ \\
\hline
\end{tabular}

Tabela 7 - Estatísticas utilizadas nos testes de comparação entre médias de duas amostras pertencentes a populações com distribuição de Von Mises (casos II e III). Os índices i e s referem-se respectivamente a estatísticas de amostras das metades inferior e superior do sistema Pirambóia.

\begin{tabular}{|c|c|c|c|c|c|c|c|c|c|c|c|c|c|c|}
\hline Amostras & $n_{i}$ & $n_{s}$ & $n$ & $r$ & $x_{0 i}$ & $x_{0 s}$ & $x_{n}$ & $R_{b i}$ & $R_{0 s}$ & $R_{O(t, s)}$ & $k_{(i, s)}$ & 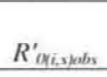 & $\begin{array}{l}R_{\text {ni.skrtitice }}^{\prime} \\
\alpha=0.05\end{array}$ & Resultado \\
\hline I-AFMc-RC e S-AFMc-RC & 166 & 36 & 202 & 0,18 & 184,77 & 125,43 & 169,56 & 0,31 & 0,54 & 0,32 & 0,67587 & 0,35 & \multicolumn{2}{|c|}{ ver Tabela 8} \\
\hline 1-AFMc-BT e S-AFMc-BT & 185 & 20 & 205 & 0,10 & 173,35 & 222,27 & 179,10 & 0,52 & 0,71 & 0,52 & 1,19105 & 0.54 & 0,52 & $\begin{array}{c}x_{a i} \neq \boldsymbol{x}_{a_{\mathrm{s}}} \\
\text { (Tabela 8) }\end{array}$ \\
\hline I-AFMc-PJ e S-AFMc-PJ & 80 & 40 & 120 & 0,33 & 245,69 & 178.27 & 216,83 & 0.43 & 0,67 & 0,43 & 0,95440 & 0,51 & 0,45 & $x_{0 i} \neq x_{0,}$ \\
\hline I-AFMc-GR e S-AFMc-GR & 39 & 32 & 65 & 0,45 & 28,915 & 242,62 & 287.73 & 0,49 & 0,82 & 0,21 & 0,42962 & 0.64 & 0.28 & $x_{n i} \neq x_{0 \mathrm{~s}}$ \\
\hline
\end{tabular}

Tabela 8 - Intervalos de confiança (95\%) das diferenças entre azimutes médios de estratificações cruzadas acanaladas obtidas nas metades inferior (índice i) e superior (índice s) do sistema Pirambóia (Caso I).

\begin{tabular}{|c|c|c|c|c|c|c|c|}
\hline Amostra & $x_{i t i}$ & $x_{i s}$ & $d=\left|x_{b i}-x_{i n}\right|$ & $v$ & $d_{\min }$ & $d_{\operatorname{mix}}$ & Resultado \\
\hline I-AFMc-RC e S-AFMc-RC & 184,77 & 125,43 & 59,34 & 36,15 & 23,19 & 95,49 & $x^{\prime}$ \\
\hline I-AFMc-BT e S-AFMc-BT & 173,35 & 222,27 & 48,92 & 29,06 & 12,77 & 77,98 & $x_{\theta i} \neq x_{i \mathrm{~s}}$ \\
\hline
\end{tabular}

paleorrelevo e geometria da bacia. Bigarella \& Salamuni (1961)e Bigarella \& Van Eeden (1970/1971) explicaram o padrão convergente de paleoventos do Arenito Botucatu (sensu lato) com ênfase no primeiro fator, enquanto Giannini et al. (1999, 2000) relacionaram a convergência de paleoventos da Formação Pirambóia preferencialmente ao segundo. Em vista da pequena resolução temporal das reconstituições paleoatmosféricas e paleocontinentais, agravada pela falta de consenso sobre a idade do sistema Pirambóia, nenhum dos dois fatores pode ser a priori descartado de uma discussão, como a que se segue, sobre a distribuição de paleoventos nesta unidade. Nesta discussão, a abordagem em separado de cada fator atende apenas ao objetivo de clareza de análise, sem implicar rejeição da possibilidade de sua atuação conjunta. $\mathrm{Na}$ abordagem do fator paleorrelevo, consideram-se adicionalmente os resultados de paleocorrentes subaquosas (no caso fluviais) e seu possível significado quanto a paleodeclives.

Paleoventose dinâmica atmosférica Bigarella \& Salamuni (1961) compararam a distribuição azimutal encontrada na Formação Botucatu sensu lato (paleoventos vindos de $\mathrm{N}$ a NE, a norte da porção centro-sul do Paraná, e de W a SW, a sul) ao padrão de circulação de ventos em roda (wheel round), peculiar dos desertos atuais de baixas latitudes. Este padrão caracteriza-se pela existência de uma zona crítica de mudança da direção dos ventos. Com base nisso, os autores interpretam que o paleodeserto Botucatu teria se desenvolvido em baixas latitudes, com zona crítica localizada no centro-sul do Paraná.

O padrão de paleoventos inferido por Bigarella \& Van Eeden (1970/1971) para o Arenito Botucatu (sensu lato) e seus equivalentes no Paraguai e Uruguai é muito similar ao observado por Bigarella \& Salamuni (1961), com o dado adicional de paleoventos de SE no Arenito Sambaíba (Bacia do Parnaíba). Baseados em analogia com o padrão de circulação atmosférica atual, os autores interpretaram os paleoventos do Arenito Sambaíba como paleoalísios de SE. Aos paleoventos de N a NE e de S a SW, observados no Arenito Botucatu, relacionaram respectivamente paleoalísios de retorno (paleoalísios de SE defletidos) e paleoventos de $W$.

Admitindo idade jurássica a cretácica inicial para o Arenito Botucatu, baseada em datações radiométricas de derrames (120130 ma, Cordani \& Vandoros 1967) intercalados aos arenitos eólicos, Bigarella \& Van Eeden (1970/1971) concebem um modelo de paleocirculação atmosférica em que os paleoventos de W seriam originários da área sobre o paleoceano Panthalassa e os alísios de SE e de retorno proviriam de uma célula de alta pressão localizada sobre o protoceano Atlântico. Desse modo, o cenário paleogeográfico da Bacia do Paraná durante o desenvolvimento do deserto Botucatu seria caracterizado por ausência de barreiras geográficas capazes de alterar o percurso das massas de ar provenientes das áreas sobre os oceanos, tanto a oeste como a leste.

Partindo da premissa de que os Arenitos Botucatu (sensu lato) correspondem ao aqui denominado sistema eólico Botucatu, a possibilidade de extensão daqueles modelos de paleocirculação ao sistema Pirambóia deve ser avaliada de dois modos diferentes, a depender das relações de idade que se admitem entre ambas unidades. Caso lhe seja atribuída idade jurássica a eocretácica, o sistema Pirambóia teria se desenvolvido em cenário paleogeográfico semelhante ao evocado por Bigarella \& Salamuni (1961) e Bigarella \& Van Eeden (1970/1971) para a Formação Botucatu (sensu lato). Os paleoventos de N, NE e, localmente, de NW equivaleriam a paleoalísios de retorno (paleoalísios de SE defletidos), derivados de uma célula de alta pressão atlântica. Os paleoventos de SW 
corresponderiam à deflexão de paleoventos de W.

Caso admitida ausência de hiato deposicional significativo entre as unidades do final do Mar Passa Dois e o sistema eólico úmido Pirambóia, torna-se razoável supor idade neopermiana a triássica para este sistema. Durante o Permiano e parte do Triássico, todas as massas continentais encontravam-se aglutinadas no supercontinente Pangea (Veevers 1989). A abertura do Oceano Atlântico não se havia iniciado ou encontrava-se em estágio embrionário. Esta situação diminui a viabilidade da interpretação dos paleoventos de NE, observados a norte do centro-sul paranaense, como paleoalísios de retorno gerados em célula de alta pressão sobre o Oceano Atlântico. Hipótese alternativa seria a destes paleoventos corresponderem a ventos alísios de NE, oriundos de uma célula de alta pressão localizada na área continental a leste e/ ou sobre o paleoceano Tethys (Parrish 1995).

Comparando-se os paleoventos inferidos para as metades inferior e superior do sistema eólico Pirambóia (Figs. 7 e 8), nota-se que a zona de convergência de paleoventos migrou para sul ao longo do intervalo de tempo envolvido no desenvolvimento do sistema. Esta migração poderia ser explicada por alterações meramente climáticas e/ou pela deriva da placa continental para norte. As reconstituições paleocontinentais apresentadas por Smith et al. (1981) não permitem confirmar nem rejeitar esta segunda possibilidade, uma vez que supõem a migração para norte da porção do Gonduana que abrange o continente sul-americano a partir do Triássico, após uma fase de deslocamento para sul no Neopermiano.

Paleocorrentes, paleoventos e topografia PALEOCORRENTES SUBAQUOSAS A grande variabilidade das paleocorrentes nas fácies subaquosas, evidenciada pelo caráter de distribuição uniforme segundo o teste de Rayleigh, pode ser característica intrínseca à geometria das formas de leito. Sejam as fácies subaquosas interpretadas como produto da migração de formas de leito em sistema fluvial entrelaçado (barras de areia ou cascalho e megaondulações superimpostas), sejam interpretadas como resultantes da dinâmica de barras e dunas subaquosas de submaré, a variabilidade das paleocorrentes pode decorrer da mistura de diferentes tipos ou hierarquias de formas de leito (ex. barras longitudinais, barras transversais e dunas subaquosas), com rumos de migração distintos. Outra possibilidade, não excludente em relação à primeira, é que a variabilidade de paleocorrentes relacionese ao próprio padrão de distribuição de um mesmo tipo de forma de leito no sistema deposicional em questão. Sob este aspecto, a presença de distribuição de freqüências aproximadamente bipolar (amostra 3, Fig. 7) em fácies (Aci) da fatia inferior do sistema Pirambóia favorece a interpretação de paleocorrentes de maré atuando paralelamente ao início da atividade do sistema eólico.

Caso fluviais, as paleocorrentes permitem inferir variações de paleodeclividade da bacia no tempo e no espaço. Assim, para o intervalo de tempo correspondente à metade inferior do sistema Pirambóia, haveria indicação de paleodeclive para SW no sudoeste de São Paulo e norte do Paraná. E para o período de tempo equivalente à metade superior, poderiam ser inferidos paleodeclives para NW, no norte e centro-leste de São Paulo, e para SW, no centro e sul do Paraná (Fig. 9).

PALEOVENTOS O uso de modelos atualistas de influência da topografia sobre os rumos de ventos formadores de campos de dunas permite explicar tanto as pequenas discrepâncias entre
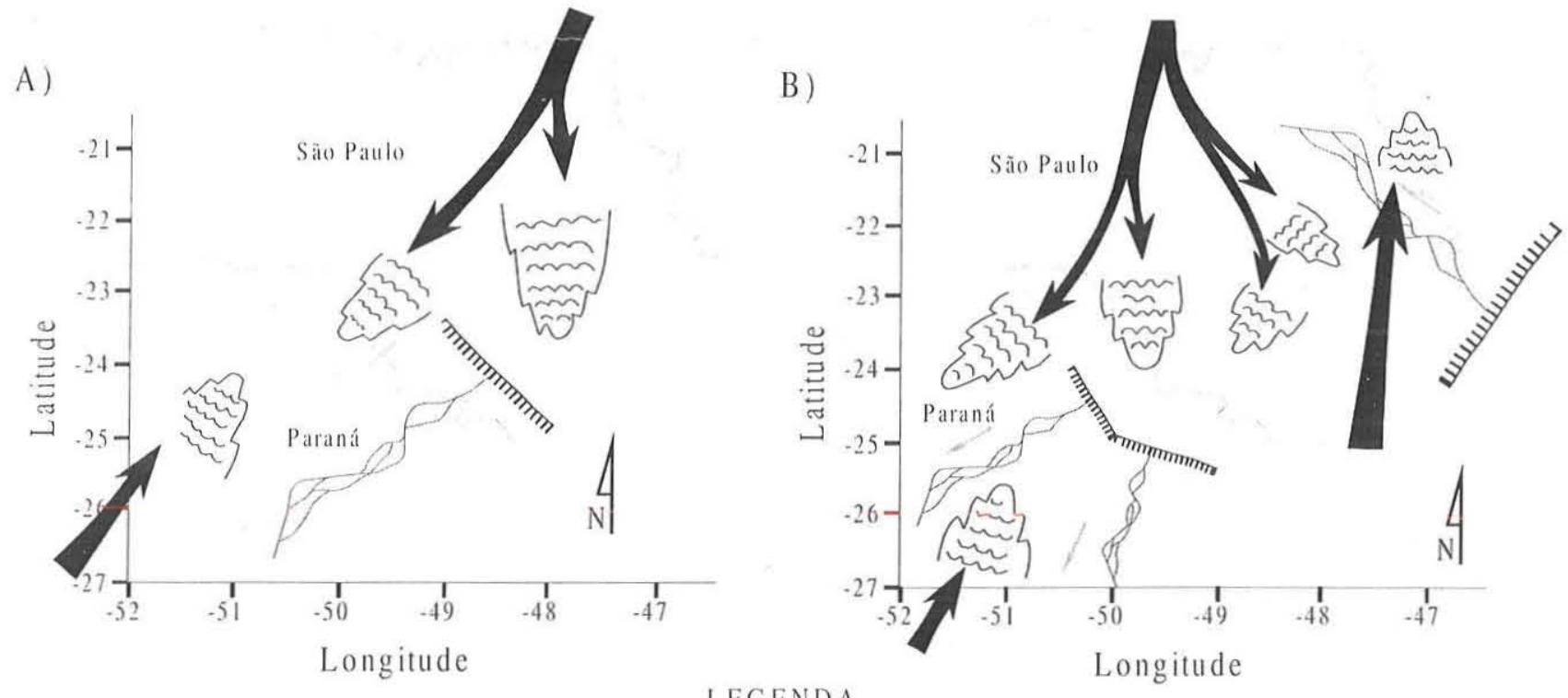

LEGENDA

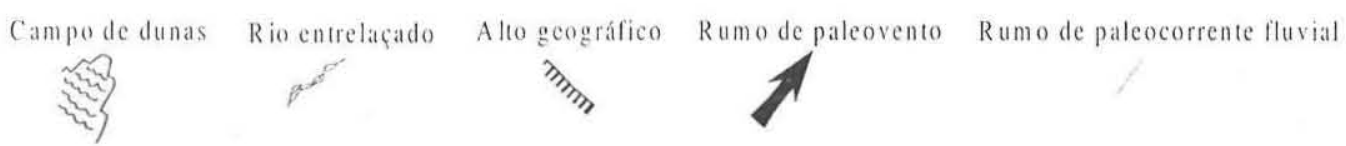

Figura 9 - Esboço do cenário paleogeográfico proposto para o sistema deposicional Pirambóia nos estados de São Paulo e Paraná. As figuras A e B correspondem, respectivamente, aos cenários paleogeográficos representados pelas metades inferior e superior da Formação Pirambóia. 
paleoventos que sopram para um mesmo hemisfério, quanto a convergência de paleoventos opostos. Em baixas latitudes, as massas de ar mais atuantes formam-se geralmente em zonas de alta pressão sobre áreas oceânicas, de onde divergem em direção aos continentes. Ao atingirem a costa, tendem a ser defletidas pelo relevo. Com isto, os ventos de regiões costeiras ou interiores vizinhas podem adquirir orientações ligeiramente distintas, desde ortogonais até paralelas à costa, dependendo da orientação relativa entre a migração das massas de ar e as feições topográficas mais marcantes. De comum em termos azimutais, estes ventos possuem a origem nas áreas oceânicas. Exemplo atual deste efeito encontra-se nos ventos responsáveis pela formação dos campos de dunas transgressivos do Nordeste brasileiro (Giannini et al. no prelo). Embora se trate de ventos alísios de leste, a orientação de migração dos campos de dunas varia de SW a NW. Por analogia, em regiões adjacentes entre si do sistema eólico Pirambóia, a variabilidade nos rumos de paleoventos que sopram para um mesmo hemisfério (Tabelas 4,5 e 6 ) pode ser explicada pela deflexão da direção primária dos paleoventos provocada pelo paleorrelevo nos limites da bacia. Uma vez introduzido em bacias semi-fechadas, em forma de golfo, como se supõe ser o caso da Bacia do Paraná durante o Permiano e o Triássico, o vento procedente de áreas oceânicas tem mais campo de atuação (fetch) ao longo do eixo maior da bacia, tendendo assim a se paralelizar às suas bordas. Tomando por base este raciocínio, a direção da linha de costa da Bacia do Paraná, durante o desenvolvimento do sistema eólico Pirambóia, seria aproximadamente paralela à direção dos paleoventos deste sistema deposicional, ou seja, NNE-SSW.

A existência de dunas com rumos de migração opostos, evidenciados pelo padrão de convergência observado no Estado do Paraná e pelos paleoventos de sul no sistema Pirambóia superior no norte de São Paulo (município de Itamoji. Fig. 8), também pode ser atribuída à presença de formas de relevo. Neste caso, deve tratar-se de elevações extensas, de modo a determinar o bloqueio das massas de ar, em vez de sua simples deflexão, e com fonte sedimentar de ambos os lados, isto é, internas à bacia, à semelhança de arcos estruturais. Estas elevações atuariam como barreiras aos ventos com maior potencial para transporte de sedimentos, produzindo zona de sombra a sotavento. Assim, na zona de sombra, o transporte eólico pode passar a ser determinado por ventos opostos, com menor capacidade de transporte de sedimentos. Além do efeito de sombra, a barreira topográfica atua como fator de redução do efluxo eólico, o que favoreceria o acúmulo de areia sobre os flancos do arco. Em menor escala, esta situação é exemplificada hoje pelos campos de dunas transgressivos da ilha de Santa Catarina (SC) e da região de Torres (RS) (Giannini et al. no prelo), os quais apresentam azimute de migração (para NE) contrário ao prevalecente na costa sul do Brasil.

\section{INTEGRANDO PALEOVENTOS E PALEOCORRENTES} SUBAQUOSAS A reconstituição final da paleogeografia do sistema eólico Pirambóia, pela integração dos dados de paleoventos e paleocorrentes subaquosas, depende de modelos de fácies mais elaborados que permitam estabelecer de modo seguro o agente deposicional responsável por estas paleocorrentes. Embora não se disponha deste modelo até o momento, é importante ressaltar que três aspectos, baseados em diferentes tipos de informações, convergem para reforçar a hipótese de atuação de paleoaltos estruturais internos à bacia:

1. A zona de inversão no padrão de paleoventos do sistema Pirambóia inferior situa-se no norte do Paraná. As paleocorrentes da época, caso fluviais, indicam declive para SW a sul desta zona. No sistema Pirambóia superior, a zona de inversão de paleoventos desloca-se para sul, e coincide geograficamente com região de inversão de paleocorrentes. Caso sejam atribuídas a rios, as paleocorrentes evidenciam a presença de um paleoalto nesta zona. Esta hipótese é compatível com a idéia de convergência de ventos devido ao bloqueio exercido por barreira topográfica.

2. O mapa de isópacas dos arenitos Pirambóia e Botucatu (Araújo et al. 1995) indica a existência de calha alongada segundo NNE, com um depocentro principal no nordeste da Argentina e dois depocentros subordinados, situados muito próximos entre si, no leste do Estado do Mato Grosso do Sul e no extremo oeste do Estado de São Paulo. A julgar pela disposição das isópacas, o depocentro principal (sul) seria separado dos dois depocentros menores (norte) por um alto estrutural alongado segundo NW, aproximadamente coincidente com of flanco sul do Arco de Ponta Grossa. A espessura comparativamente menor dos depósitos do sistema Pirambóia nas regiões de Piraju (SP) e Santo Antônio da Platina (PR) é corroborada por dados de seções geológicas levantadas ao largo dos estados de São Paulo e Paraná (Donatti 2002).

3. Fácies rudáceas na metade inferior do sistema Pirambóia foram encontradas apenas nas regiões de Piraju (SP) e Santo Antônio da Platina (PR), situadas sobre o alinhamento magmático de Guapiara, flanco norte do arco de Ponta Grossa. Independe da incerteza quanto ao agente deposicional (correntes fluviais ou de marés), estes depósitos podem ser relacionados à proximidade de área fonte e, portanto, à existência local de paleoalto.

A hipótese mais simples para explicar a compartimentação da sedimentação eólica transversal ao eixo maior da bacia seria admitir a existência de altos alongados na direção do Arco de Ponta Grossa, cujo soerguimento teria se acentuado no decorrer da sedimentação, como reflexo da intumescência inicial pré-derrame. Este modelo explica o aparecimento de fácies rudáceas no topo do sistema Pirambóia. Conta a seu favor também o fato de que a principal zona de convergência e/ou desvio de influxos coincide, durante toda a sedimentação Pirambóia, com o flanco norte do Arco de Ponta Grossa.

Paleoventos versus linhas de tempo Outra hipótese que pode ser evocada para explicar as mudanças de paleoventos entre diferentes regiões e intervalos estratigráficos do sistema Pirambóia, sem excluir necessariamente os fatores paleocirculação e paleorrelevo, diz respeito ao caráter possivelmente erosivo do topo das fácies eólicas do sistema Pirambóia (Caetano-Chang 1997, Donatti et al. 2001), o que criaria uma superfície diácrona, parcialmente demarcada pelas fácies grossas. Desse modo, uma mesma fatia estratigráfica delimitada com base na espessura da unidade abrangeria diferentes fatias de tempo em regiões vizinhas e os paleoventos detectados em cada fatia não pertenceriam a um mesmo cenário paleogeográfico. A melhor avaliação desta hipótese somente será possível, entretanto, quando se dispuser de informações precisas sobre o intervalo de tempo registrado pela unidade, em diferentes porções da bacia.

Conclusões Com base nos dados de rumo preferencial assim obtidos, deduz-se um padrão de paleoventos caracterizado pelo predomínio de direções sub-paralelas ao alongamento geral da bacia e pela ocorrência de uma zona de convergência, que migrou da porção norte para a centro-norte do Paraná durante o desenvolvimento da sedimentação. O padrão de paleoventos reflete convergência de massas de ar, em escala de circulação atmosféri- 
ca global e/ou regional, neste último caso relacionada a bloqueio exercido por acidente de relevo. O sistema Pirambóia contaria assim com dois influxos eólicos, um com fonte preferencial a norte, $\mathrm{e}$ outro com fonte a sul. A redução de efluxo destes dois vetores convergentes de transporte eólico, necessária para produzir a acumulação, seria determinada pela perda de competência em função da distância às fontes, intrínseca ao padrão de paleocirculação atmosférica global, e/ou pela existência de barreira geográfica, que serviria de obstáculo aos ventos de sul, na porção norte, e aos ventos de norte, na porção sul.

A coincidência entre as áreas de inversão de paleoventos e paleocorrentes subaquosas, a distribuição geográfica de fácies rudáceas e as zonas de adelgaçamento da espessura indicadas por mapas de isópacas reforçam a idéia de existência de paleoaltos estruturais internos à bacia, durante o desenvolvimento do sistema. Entretanto, a origem duvidosa das paleocorrentes subaquosas (fluviais e/ou costeiras?) impossibilita utilizá-las de modo seguro para inferir outros aspectos da paleogeografia e proveniência sedimentar.

Agradecimentos Os dados deste artigo foram obtidos no âmbito do projeto de pesquisa "As Formações Pirambóia e Botucatu nos Estados de São Paulo e Paraná", financiado pela Fundação de Amparo à Pesquisa do Estado de São Paulo (FAPESP, Processo 98/00161-0). Os autores agradecem ao Prof. Dr. Armando Márcio Coimbra (in memoriam) e a Eva Kaiser Mori e Patrícia Lopes Fonseca (bolsistas PIBIC-CNPq, IG-USP), que participaram de atividades de campo do projeto. Agradecem também ao Prof. Dr. Jorge Kazuo Yamamoto (IG-USP) pela revisão dos métodos estatísticos utilizados no tratamento dos dados e pelas sugestões referentes à redação e edição do artigo. Aos revisores da RBG pelas sugestões ao manuscrito.

\section{Referências}

Araújo L.M., França A.B., Potter P.E. 1995. Giant Mercosul aquifer of Brazil. Argentina, Uruguay, and Paraguay: hydrogeologic maps of Botucatu. Pirambóia. Rosário do Sul, Buena Vista. Misiones and Tacuarembó formations. (Portuguese, Spanish, English). Universidade Federal do Paraná-PETROBRÁS, Curitiba, 8 mapas, $16 \mathrm{pp}$.

Assine M.L. 1993. O eólico e o fluvial na Formação Pirambóia. In: SBG, Simp. Sul-Brasileiro Geol., V, Boletim de Resumos e Programas, p. 53-54.

Bigarella J.J. 1970/1971. Wind pattern deduced from dune morphology and internal structures. Bol. Paran. Geoc., 28-29:73-114.

Bigarella J.J. \& Van Eeden O.R. 1970/1971. Mesozoic paleowind patterns and the problem of continental drift. Bol. Paran. Geoc., 28-29:115144.

Bigarella J.J. \& Salamuni R. 1961. Early Mesozoic wind patterns as suggested by dune bedding in the Botucatu Sandstone of Brazil and Uruguay. Geol. Soc. Am. Bull., 72:1089-1106.

Caetano-Chang M.R. 1997. A Formação Pirambóia no centro-leste do Estado de São Paulo. Tese de Livre Docência, Instituto de Geociências e Ciências Exatas, Universidade Estadual Paulista, 196 p.

Caetano-Chang M.R., Wu F.T., Brighetti J.M.P. 1991. Caracterização eólica de arenitos da Formação Pirambóia e Botucatu, proximidades de São Pedro (SP). In: SBG, Simpósio de Geologia do Sudeste, 2, Atas, p. 53-58.

Cordani U.G. \& Vandoros P. 1967. Basaltic rocks of the Paraná Basin. In: Bigarella J.J., Becker R.D., Pinto J.D. (eds) Problems in Brazilian Gondwana Geology. Universidade Federal do Paraná, pp.: 207. 231 .

Donatti L.M. 2002. Faciologia, proveniência e paleogeografia das Formaçôes Pirambóia e Botucatu no Estado do Paraná. Dissertação de Mestrado, Instituto de Geociências, Universidade de São Paulo, $135 \mathrm{p}$.

Donatti L.M., Sawakuchi A.O., Giannini P.C.F., Fernandes L.A. 2001. The Pirambóia-Botucatu sucession (Late Permian-Early Cretaceous, Paraná Basin, São Paulo and Paraná States): two contrasting eolian systems. Anais Acad. Bras. Ciênc., 73(3): 465.

Fúlfaro V.J. 1972. The Parana Basin upper Permian and lower Mesozoic stratigraphic succession. An.Acad.Brasil.Ciênc.,44 (suplemento): $147-148$
Fúlfaro V.J. \& Bósio N.J. 1968. Novas observações sobre a faciologia do Arenito Botucatu no Estado de São Paulo. In: SBG, Congr. Bras. Geol., 22, Bol. Resumos, p. 57-59.

Giannini P.C.F., Fernandes L.A., Donatti L.M., Sawakuchi A.O., Mori E.K., Coimbra A.M. 1999. Rumos de paleoventos na Formação Pirambóia nos estados de São Paulo e Paraná. In: Simp. Geol. Sudeste, 6, Boletim Resumos, p. 72.

Giannini P.C.F., Assine M.L., Barbosa L.M., Barreto A.M.F., Carvalho A.M., Claudino-Sales V., Maia L.P., Martinho C.T., Peulvast J.P., Sawakuchi A.O., Tomazelli L.J. Dunas eólicas costeiras e interiores. In: C.R.G. Souza, K. Suguio, P.E. de Oliveira, A.M.S. Oliveira (eds.) Quaternário do Brasil. ABEQua (no prelo).

Lavina E.L. \& Faccini U.F. 1993. Formações Pirambóiae Sanga do Cabral: um episódio de desertificação na Bacia do Paraná ao final do Permiano? In: Simp. Cronoestratigrafia Bacia Paraná, I. Bol. Res. Expandidos, p. 94-95.

Matos S.L.F. 1995. O contato entre o Grupo Passa Dois e a Formação Pirambóia na borda leste da Bacia do Paraná no Estado de São Paulo. Dissertação de Mestrado, Instituto de Geociências, Universidade de São Paulo, 110 p.

Mardia K.V. 1972. Statistics of directional data. Academic Press, London, $357 \mathrm{pp}$.

Mckee E.D. 1982. Sedimentary structures in dunes of the Namib desert, south west Africa. Geol. Soc. Am., Spec. Papers, 118:1-64.

Paraguassu A.B. 1968. Contribuição ao estudo da Formação Botucatu sedimentos aquosos, estruturas sedimentares e silicificação. Tese de Doutoramento, Escola de Engenharia de São Carlos, Universidade de São Paulo, 131 p.

Parrish J.T. 1995. Geologic evidence of Permian climate. In: Scholle P.A., Peryt T.M., Ulmer-Scholle D.S. (eds.) The Permian of northern Pangea, 1: Paleogeography, paleoclimates, Stratigraphy. SpringerVerlag, pp.: 53-61.

Rohn R. 1994. Evolução ambiental da Bacia do Paraná durante o Neopermiano no leste de Santa Catarina e do Paraná. Tese de Doutoramento, Instituto de Geociências, Universidade de São Paulo, $2 \mathrm{v}, 386 \mathrm{p}$

Scotese C.R. \& Langford R.P. 1995. Pangea and the paleogeography of the Permian. In: Scholle P.A., Peryt T.M., Ulmer-Scholle D.S. (eds.) The Permian of the northern Pangea I-paleogeography, paleoclimates, stratigraphy. Springer-Verlag, pp.: 3-19. 
Paleoventos e paleocorrentes subaquosas do sistema deposicional Pirambóia nos Estados de São Paulo e Paraná, Bacia do Paraná: estudo baseado em análise estatística de dados azimutais

Smith A.G., Hurley A.M., Briden J.C. 1981. Phanerozoic paleocontinental world maps. Cambridge University, Cambridge, 102 pp.

Soares P.C. 1973. O Mesozóico gondwânico no Estado de São Paulo. Tese de Doutoramento, Fac. Filos. Ciências e Letras, Universidade Estadual Paulista, $153 \mathrm{p}$

Soares P.C. 1975. Divisão estratigráfica do Mesozóico do Estado de São Paulo. Rev. Bras.Geoc., 5:229-251.

Souza A., Sinelli O., Gonçalves N.M. 1971. Nova ocorrência fossilífera na Formação Botucatu. In: SBG, Congr. Bras. Geol., 25, Anciis, 2. p. 281-295.

Tucker M.E. 2001. Sedimentary petrology: an introduction to the origin of sedimentary rocks. Blackwell Science, Oxford, 262 pp..

Turner S., Regelous M., Kelley S., Hawkesworth C., Mantovani M. 1994. Magmatism and continental break-up in the South Atlantic: high precision ${ }^{40} \mathrm{Ar}^{-{ }^{30}} \mathrm{Ar}$ geochronology. Earth Planet. Sci. Lett.,
121:333-348.

Veevers J.J. 1989. Middle/late Triassic (230 $\pm 5 \mathrm{Ma})$ singularity in the stratigraphic and magmatic history of the Pangean heat anomaly. Geology, 17:784-787.

Vieira A. J. \& Maingué E. 1973. Geologia de semi-detalhe do centro e nordeste do Paraná e centro-sul de São Paulo. Ponta Grossa, Petrobras/Desul, Relatório Petrobras/Desul 425, 49p.

Washburne C.W. 1930. Geologia do petróleo no Estado de São Paulo. Bol. Com. Geogr: Geol. Est. S. Paulo, 22:1-282.

Manuscrito A-1454

Recebido em 29 de julho de 2003

Revisão dos autores em 20 de março de 2004 Revisão aceita em 30 de março de 2004 